\title{
Results of Intra-lesional Triamcinolone in the Treatment of Alopecia Areata
}

\author{
MA WAHAB
}

Summary:

During the period of January 2001 to December 2004, a total of 40 cases (30 male and 10 female) of 10 to 50 years age groups were studied at the Department of Dermatology and Venereology, Combined Military Hospital (CMH), Dhaka Cantonment, Dhaka to find out the results of intralesional triamcinolone in the treatment of localized alopecia areata. Diagnosis of the cases was based on history and clinical findings. According to number of alopecic patches, the patients were categorized into three groups (group-I having less than three patches, group-II having

Introduction:

Alopecia areata(AA) is characterized by rapid and complete loss of hair in one or more round or oval patches usually on the scalp, the bearded area, the eyebrows, the eyelashes and rarely on other hairy areas of the bodies ${ }^{1,2,3}$. There is no exact data about the incidence of alopecia areata. In Bangladesh, no study on the issue was done earlier. The exact cause is unknown. Most evidence points toward it is being an autoimmune disease modified by genetic factors and aggravated by emotional stress ${ }^{4,5,6}$. Some patches may show growth of hair in a few weeks without any treatment. Many modalities of treatment are available like intralesional steroid infiltration, topical potent steroid, contact sensitizers [dinitro chlorobenzene (DNCB), squaric acid dibutyl ester and diphenyl cyclopropenone], anthralin, tacrolimus, pimecrolimus, topical minoxidil, topical PUVA, topical nitrogen mustard, interferon-gamma, excimer laser, systemic steroid, cyclosporine etc ${ }^{7,8,9}$.

Intralesional triamcinolone $3-5 \mathrm{mg} / \mathrm{ml} / \mathrm{sqcm}$ are usually effective ${ }^{10}$. It should be given 4-6 weeks interval. The mechanism of action of intralesional steroid as immunosuppressive and antiinflammatory ${ }^{11}$. It is the treatment of choice for localized patches of AA. This

Address of correspondence: Lt. Col (Dr.) Md. Abdul Wahab, MBBS, DDV, MCPS, FCPS, Senior Classified Specialist in Dermatology \& Venereology, Skin Department, Combined Military Hospital, Dhaka Cantonment, Dhaka. three to five patches and group-III having more than five patches). Intralesional triamcinolone was given 3-5 mg/ sqcm at monthly interval for 3-5 months according to their response.

Good response was observed in $77 \%$ in group-I, $50 \%$ in group-II and $25 \%$ in group-III. It appears that intralesional triamcinolone is safe and effective in localized and limited number of patches in alopecia areata, if treated earlier.

(J Bangladesh Coll Phys Surg 2006; 24 : 110-113)

study has been designed to evaluate the effectiveness of intralesional injection of triamcinolone in the treatment of AA.

\section{Materials and method:}

This study was carried out during the period of January 2001 to December 2004 at the Department of Dermatology \& Venereology, CMH, Dhaka Cantonment, Dhaka including one year follow up. This study was conducted among 40 cases of localized alopecia areata aged 10 to 50 years. The sample was selected randomly. All the cases were treated as outdoor patients. Following criterias were used to select the study population:

a. Inclusion criterias:

I) Patients having localized patches of alopecia areata,

II) Age between 10-50 years,

III) Both male and female patients,

IV) Those who were willing to participate in this study.

b. Exclusion criterias:

I) The patients who were suffering from serious illness,

II) Age below 10 years and above 50 years,

III) Widespread involvement of alopecia (alopecia totalis and alopeica universalis),

IV) Those who were declined to give interview. 
Diagnosis of the cases was based on history and clinical findings. Routine investigations were done to exclude other diseases like tinea capitis, secondary syphilis, discoid lupus erythematosus and trichotillomania. All the tests were done in the laboratory of Armed Forces Institute of Pathology, Dhaka Cantonment, Dhaka. All the patients were unresponsive to treatment with topical application of potent steroid. The patients were categorized into three groups according to number of lesions (patches). In group-1 the lesions were less than three, in group-II three to five, and in group-III more than five.

Intralesional injection of triamcinolone: $10 \mathrm{mg}$ of intralesional steroid preparation mixed with lignocaine solution and prepared $3-5 \mathrm{mg} / \mathrm{ml}$ and then given intradermally $1 \mathrm{ml} / \mathrm{cm}^{2}$ at monthly interval for 3-5 months. The cases were followed up monthly for another one year.

Improvement was noted on the basis of hair growth as follows:

$$
\begin{array}{ll}
\text { Good } & \text { - complete growth of hair } \\
\text { Fair } & \text { - incomplete growth of hair } \\
\text { Poor } & \text { - no growth of hair. }
\end{array}
$$

In all cases injection triamcinolone was given intralesionally at monthly interval three to five doses according to response of patients. In some cases side effects were seen (atrophy, erythema and telangiectasia).

\section{Results:}

Among the 40 cases, $20(50 \%)$ were between the age group of 20 and 30 years. The mean age of the cases was 24.70 years with standard deviation of \pm 9.20 years (Table-I). The distribution of the cases by sex shows that thirty were male and ten were female (Table-II). Twenty five cases suffered from the symptoms for less than six months duration followed by ten cases for six months to one year and five cases more than one year duration (Table-III). In group-I, twenty six cases were having less than three localized patches followed by 10 in group-II having 3-5 localized patches and four in group-III having more than five localized patches of AA(Table-IV).
Table-I

Shows the distribution of age of the study population $(n=40)$.

\begin{tabular}{lcc} 
Age in years & Number of patients & Percentage \\
\hline $10-20$ & 08 & 20 \\
$20-30$ & 20 & 50 \\
$30-40$ & 07 & 17.50 \\
$40-50$ & 05 & 12.50 \\
\hline Mean $\pm \mathrm{SD}=24.70$ & years \pm 9.20 years
\end{tabular}

Table-II

Shows the sex distribution $(n=40)$

\begin{tabular}{lcc} 
Sex & Number of patients & Percentage \\
\hline Male & 30 & 75 \\
Female & 10 & 25 \\
\hline
\end{tabular}

Table-III

Shows the duration of lesions $(n=40)$

\begin{tabular}{lcc} 
Duration & Number of patients & Percentage \\
\hline$<6$ months & 25 & 62.50 \\
6 months to 1 year & 10 & 25 \\
Over 1 year & 05 & 12.50 \\
\hline
\end{tabular}

Each group of the patients were observed separately. In group-I, good response was found in twenty cases followed by fair response in two and poor response in four cases; in group-II, good response was found in five cases followed by fair in two and poor response in three cases and in group-III, good response was found in one case followed by fair in one and poor response in two cases (Table-V). The side effects like atrophy, erythema, telangiectasia etc. was found in four cases in group-I, three in group-II and two cases in group-III (Table-VI). During the follow up period, the relapse was found in two cases in group-I, two in group-II and one case in group-III (Table-VII). 
Table-IV

Shows the grouping of the patients according to number of patches $(n=40)$

\begin{tabular}{lccc} 
Group & Number of lesions & Number of patients & Percentage \\
\hline I & 3 & 26 & 65 \\
II & $3-5$ & 10 & 25 \\
III & $>5$ & 04 & 10 \\
\hline
\end{tabular}

Table-V

Shows the result of treatment $(n=40)$

\begin{tabular}{|c|c|c|c|c|c|c|}
\hline \multirow[t]{2}{*}{ Response } & \multicolumn{2}{|c|}{ Group-I } & \multicolumn{2}{|c|}{ Group-II } & \multicolumn{2}{|c|}{ Group-III } \\
\hline & $\begin{array}{c}\text { Number of } \\
\text { patients }\end{array}$ & Percentage & $\begin{array}{c}\text { Number of } \\
\text { patients }\end{array}$ & Percentage & $\begin{array}{c}\text { Number of } \\
\text { patients }\end{array}$ & Percentage \\
\hline Good & 20 & 77 & 05 & 50 & 01 & 25 \\
\hline Fair & 02 & 7.50 & 02 & 20 & 01 & 25 \\
\hline Poor & 04 & 15.50 & 03 & 30 & 02 & 50 \\
\hline
\end{tabular}

\section{Table-VI}

\begin{tabular}{lccc} 
Group & Shows the side effect $(n=40)$ & \\
& $\begin{array}{c}\text { Number of patients } \\
\text { showing side effects } \\
\text { (atrophy, erythema, telangiectasia) }\end{array}$ & Percentage \\
\hline I & 26 & 04 & 15.38 \\
II & 10 & 03 & 30 \\
III & 04 & 02 & 50 \\
\hline
\end{tabular}

Table-VII

Shows frequency of relapse during follow up period

\begin{tabular}{lccc} 
Grouping & $\begin{array}{c}\text { Number of patients of hairs } \\
\text { complete regrowth }\end{array}$ & $\begin{array}{c}\text { Number of } \\
\text { frequency of relapse }\end{array}$ & Percentage \\
\hline I & 20 & 02 & 10 \\
II & 05 & 02 & 40 \\
III & 01 & 01 & 100 \\
\hline
\end{tabular}

\section{Discussion:}

In the present study, it has been observed that intralesional triamcinolone was effective in the treatment of AA particularly in localized AA. In group-I, good response was found in $77 \%$ cases followed by fair response in $7.5 \%$ cases, in group-II, good response was found in $50 \%$ cases followed by fair response in $20 \%$ cases and in group-III, good response was found 
in $25 \%$ cases followed by fair response in $25 \%$ cases. So intralesional steroid appears to be more effective than potent steroid which has been previously used by these patients particularly in localized limited alopecia areata. Intralesional triamcinolone can be given safely in appropriate doses in both children and adults.

The main mechanism of action of intralesional steroid in AA are anti-inflammatory and immunosuppressive.

Other drugs like DNCB, squaric acid dibutyl ester, diphenylcyclopropenone, anthralin, tacrolimus, pimecrolimus, topical minoxidil, topical PUVA, systemic steroid, cyclosporine etc. can be used in the treatment of $\mathrm{AA}^{12,13,14}$. But all these drugs may induce serious side effects like contact dermatitis, hypertension, phototoxicity, kidney damage etc ${ }^{15,16}$. So, considering the side effects and effectiveness intralesional triamcinolone is safe and effective particularly in early and localized cases of AA, if treated earlier.

In this study, intralesional triamcinolone was found highly effective in localized with short duration AA cases. It is a simple out patient procedure for the treatment of localized AA and also side effects is less than the other modalities of treatment.

\section{Reference :}

1. Freedberg IM, Elisen AZ, Wolft K, Auster KF, Gordsmith LA, Katz SIL. In: Fitzpatrick's Dermatology in General Medicine, Sixth edition. Toronto: MC Growhil Co 2003. 641-3.

2. RB Odom, WD James, TG Berger. In: Andrews diseases of Skin, Ninth edition. Philadelphia: W.B Saunders company 2000. 943-5
3. Rork A. In: Textbook of Dermatology, Sixth edition. London: Blackwell Scientific Publication 1999. 2925-7.

4. Stephen E, Wolventon MD. In: Comprehensive Dermatologic Drug Therapy, Second edition. Philadelphia: WB Saunders Co 2001. 559-564.

5. Fiedler VC, Alaiti S. Treatment of alopecia areata. Dermatol Clin 1996; 14: 733-7.

6. Slodownik D, Ingber A. The use of tacrolimus in dermatology. Harefuah 2003; 142: 770-4.

7. Namazi MR, Handjani F. An immunologic mechanism for the therapeutic efficacy of minoxidil in alopecia areata. $\mathrm{J}$ Drugs Dermatol 2004; 3: 129-30.

8. Gundogan C, Greve B, Raulin C. Treatment of alopecia areata with the 308-nm xenon chloride excimer laser. Laser Surg Med 2004; 34: 86-90.

9. Arca E, Musabak U, Akar A, Erbil AH, Tastan HB. Interferon-gamma in alopecia areata. Eur J Dermatol 2004; $14: 33-6$

10. Assouly P. Alopecia areata: update on therapy. Ann Dermatol Venerol 2002; 129: 831-6.

11. Kietzmann H, Hardung H. Treatment of alopecia areata with diphenylcyclopropenone. Acta Derm Venereol 1985; 65: $274-5$

12. Janniger CK. Alopecia areata. Cutis 1992; 50: 347-9

13. Micali G, Cicero RL, Nasca MR, Sapuppo A. Treatment of alopecia areata with squaric acid dibutylester. Int $\mathrm{J}$ Dermatol 1996; 35: 52-6.

14. Price VH. Alopecia areata: clinical aspects. J Invest Dermatol. 1991; 96: 68

15. Kalam A, Tahseen MD, Islam SF, Rahmatullah MD, Faruqi NA. Dinitrochlorobenzene therapy in alopecia areata. J Indian Med Assoc 1991; 89:9-10.

16. Tosti A, Piraccini BM, Pazzaglia M, Vincenzi C. Clobetasol propionate $0.05 \%$ under occlusion in the treatment of alopecia areata. J AM Acad Dermatol 2003; 49: 96-8. 